\title{
Segmental Artery Injury During Anterior Column Realignment: A Case Report and Review of the Literature
}

\author{
Elliot Pressman MD, Ryan Screven MD, Brooks Osburn MD, Sara Hartnett MD \\ and Puya Alikhani MD
}

Department of Neurosurgery and Brain Repair, University of South Florida, Tampa, FL, USA

\begin{abstract}
Background: Anterior column realignment $(A C R)$ is a minimally invasive technique used to restore lumbar lordosis and improve sagittal balance. The most feared complication from ACR includes injury to the great vessels. Segmental artery injuries are also a possible complication, although sparsely reported. We report such a case.

Case Description: During anterior longitudinal ligament release at L3-4, the L3 segmental artery was injured. Intraoperative angiogram and coiling were performed. Our patient remained hemodynamically stable, with the exception of during the postoperative period when his hemoglobin level fell five points.

Discussion: This patient was at risk for this complication due to the tortuosity of his vessels and his osteophytes. This injury can be treated concurrently with endovascular embolization if equipment and personnel are readily available. Ultimately, segmental artery injury does not appear to be as morbid as great vessel injury, if addressed emergently.
\end{abstract}

Keywords: Anterior Column Realignment; Lateral Lumbar Interbody Fusion; Radicular Artery; Segmental Artery; Vascular System Injuries; Endovascular Hemostasis

\section{BACKGROUND}

Adult spinal deformity is a wide-ranging, nebulously classified disease that plagues a significant number of people. In patients with adult spinal deformity, poor sagittal balance has been found to be a reliable predictor of poor functional status and quality of life [1-3]. Correction of this sagittal imbalance is paramount to improving outcomes. Traditionally, this has been performed using open posterior approaches.

Within the last decade, minimally invasive techniques such as the anterior column realignment (ACR) have been used to restore lumbar lordosis and improve sagittal balance [4]. With this procedure, anterior longitudinal

\section{Corresponding author:}

Puya Alkhani MD, Department of Neurosurgery and Brain Repair, USF Health South Health Tampa Center, 2 Tampa General Circle, Tampa, FL 33606, USA.

Email: palikhan@usf.edu

(C) 2021 CC BY 4.0 - in cooperation with Depts. of Cardiothoracic/ Vascular Surgery, General Surgery and Anesthesia, Örebro University Hospital and Örebro University, Sweden ligament (ALL) transection with partial anterior annulotomy and discectomy are performed through a lateral transpsoas approach [4-6]. Following this, a lordotic or hyperlordotic cage is placed to fully capitalize on the now lengthened anterior column and restore proper sagittal balance.

The most feared perioperative complications from ACR include injury to nearby structures such as the great vessels (iliac vessels, abdominal aorta, or inferior vena cava), visceral organs, or nearby nerves and plexuses [7-12]. The surgeon should take great care to identify these structures on preoperative imaging as these injuries can be fatal or significantly impact patient quality of life. While not as life threatening, segmental artery injuries during this surgery have also been discussed as a possible complication. Three were reported in a survey of 13,004 patients conducted by Uribe and Deukmedjian, although these were never detailed in the literature [8]. In this report, we describe a patient who suffered a segmental artery injury during ACR; we hope, by sharing these details, to prevent other surgeons from making a similar error and to guide them if facing this same situation. 


\section{CASE DESCRIPTION}

\section{Clinical Presentation}

A male in his 60 s presented to the emergency department at our facility for back pain, bilateral posterior leg pain, worsening weakness of his bilateral lower extremities, and gait ataxia. On examination, the patient's strength was $4 / 5$ throughout his bilateral lower extremities, although his right lower extremity was weaker than his left, he had decreased sensation in his bilateral lower extremities without any pattern, and experienced hyporeflexia. He showed no Babinski's reflex or clonus. The rest of his neurologic exam was intact, with no upper extremity deficits. Past history was significant for a C3-4 anterior cervical discectomy and fusion 5 years prior, and a spinal cord stimulator placement at T9-10 about 1 year prior, which had given him mild pain relief. The patient's preoperative films are seen in Figure 1. After discussion of the risks and benefits of surgery, he agreed to proceed with L3-5 lateral lumbar interbody

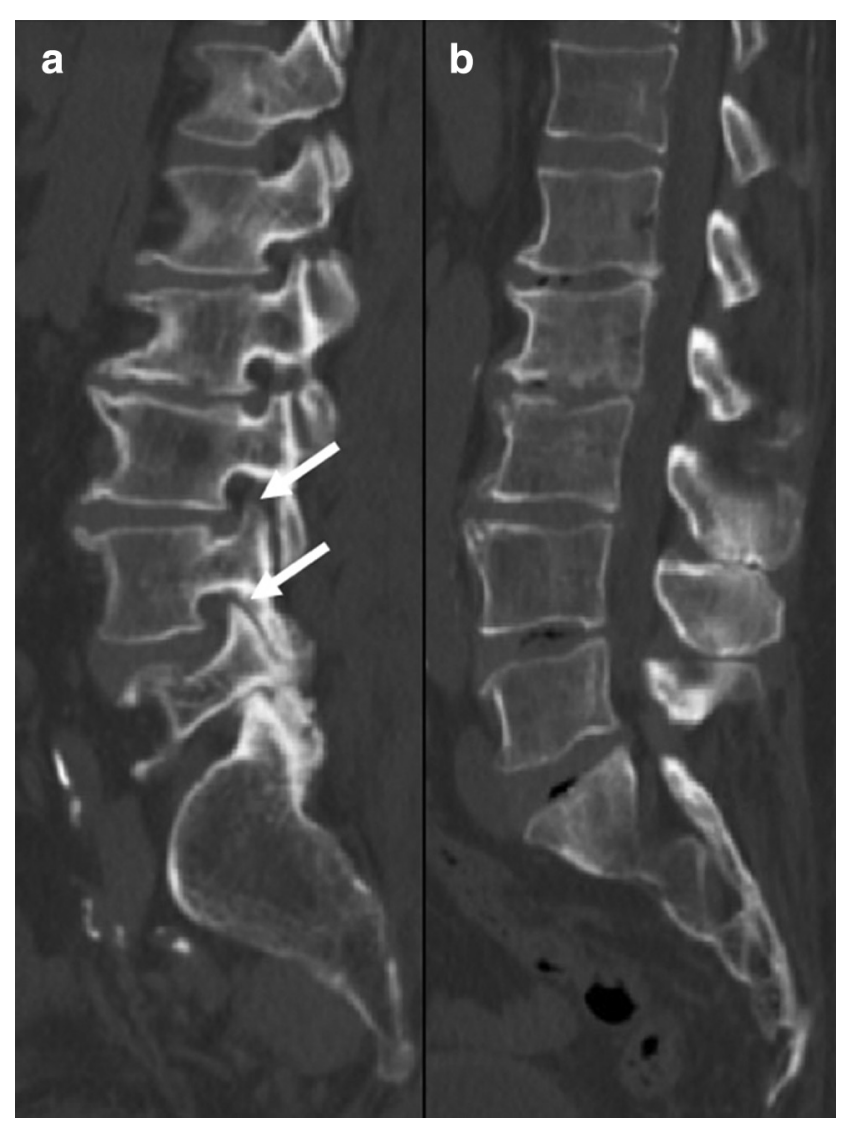

Figure 1 Preoperative images for patient described. (a) Sagittal computed tomography (CT) image showing the left neural foramina. The foramina at L3-4 and L4-5 appear significantly compressed, as demarcated by white arrows. (b) Sagittal CT image showing the spinal canal at its greatest diameter. Degenerative disk disease is seen with collapsed disk spaces at L2-3, L3-4, and L4-5. fusion (LLIF) and ACR. The patient's preoperative hemoglobin was $13.7 \mathrm{~g} / \mathrm{dl}$.

\section{Operative Procedure}

After intubation and induction of general anesthesia, the patient was turned to the lateral position, right side up. We localized the L4-5 level using fluoroscopy. After sterile prepping and draping, a skin incision was made and we reached the lateral disk space via the retroperitoneal space. Our retractors were placed and stimulated, which showed safe docking of the system. Thorough discectomy was performed, the disk space was prepared, and a $10 \times 22 \times 60-\mathrm{mm}^{3}$ cage with allograft was placed. We then removed the retractor system, and X-rays confirmed satisfactory cage placement.

We shifted to the L3-4 disk space and docked our retractor system. Discectomy was begun using a curette and Kerrison rongeurs. We placed a small retractor between the aorta and ALL. Under direct visualization, the ALL was sharply transected with a knife halfway to the mid vertebral body, at which point we advanced the retractor all the way to the contralateral pedicle. During the final cut of the ALL, some red blood appeared on the contralateral side. We packed the area with Surgicel ${ }^{\circledR}$ Fibrillar $^{\mathrm{TM}}$ and Floseal, which stopped the bleeding, and called the Vascular Surgery team for intraoperative consultation.

The vascular surgeons inspected the bleeding area and recommended closure of the area for the time being as well as further endovascular assessment, because the patient was hemodynamically stable, the wound was "extremely small and extremely deep", and the equipment was available in the operating room. After irrigation and hemostasis with packing, we removed the retractor and closed the incision in layers.

The patient was rotated to the supine position. The right groin was prepped, and field was sterilely draped. Access was achieved via a direct stick into the right common femoral artery. After placement of the sheath, the diagnostic catheter was advanced to the L 3 vertebral body. Diagnostic arteriography showed a blush from a left lumbar artery at the area of presumed bleeding (Figure 2). This lumbar artery was accessed with a re-curved catheter, and one long coil was inserted to completely obstruct the lumen. Afterward, arteriography demonstrated that the bleeding had ceased (Figure 3). Catheters were removed and hemostasis was achieved using a Mynx ${ }^{\circledast}$ device. The patient was hemodynamically stable throughout the entire procedure.

\section{Postoperative Course}

Postoperatively, the patient reported his symptoms had improved. He denied any new neurologic deficits, and his bilateral lower extremities were now full strength throughout, with intact sensation. On postoperative 


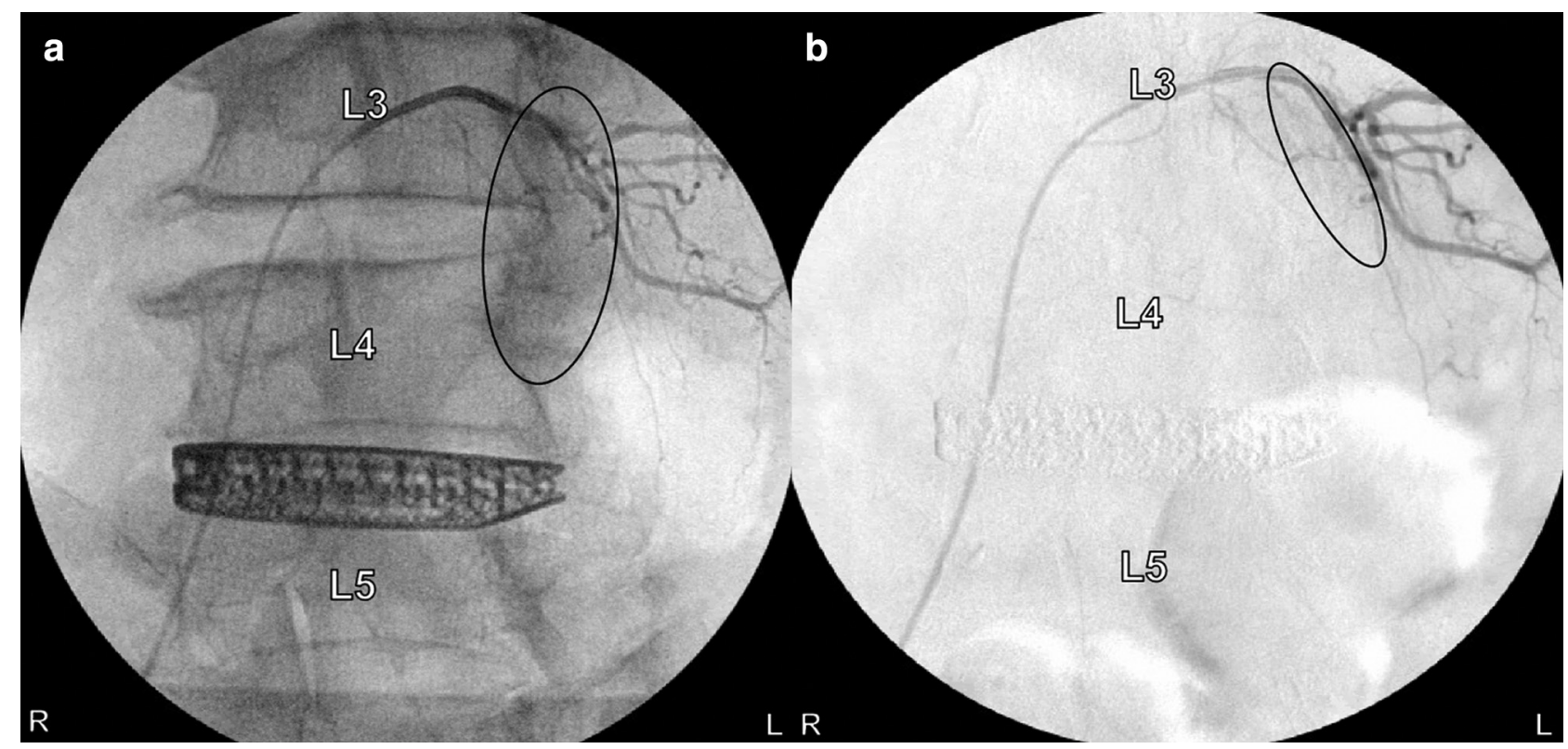

Figure 2 Intraoperative images before coil placement. (a) A still anteroposterior X-ray after dye injection into the left L3 segmental artery. The blush demonstrating active bleeding is encircled. Note how the segmental artery branches sag inferiorly and are tortuous. (b) A still image from a digitally subtracted anteroposterior angiogram is shown. A small area with a slight blush is encircled.

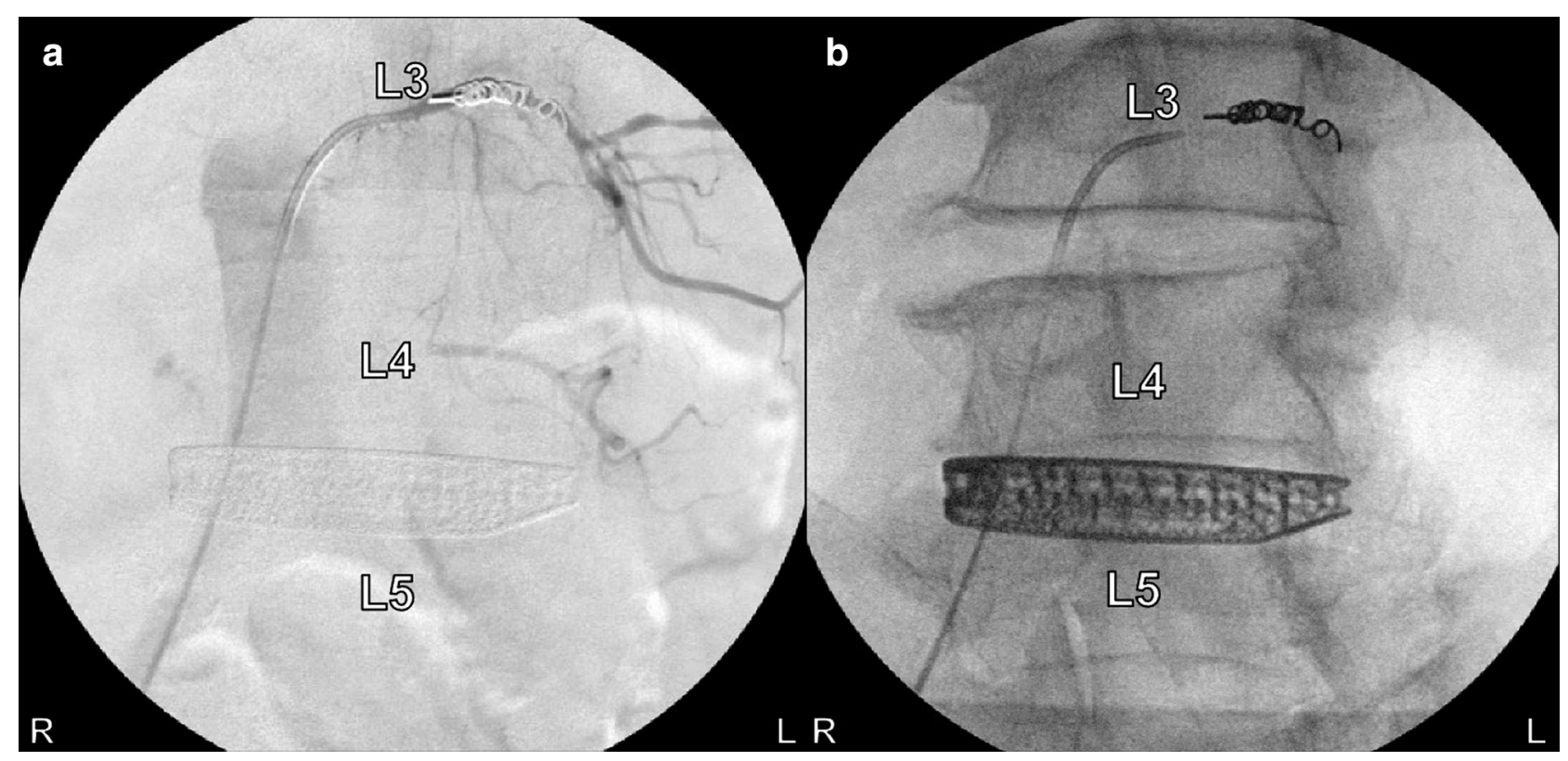

Figure 3 Intraoperative angiography images after coil placement into the left L3 segmental artery. (a) Anteroposterior digital subtracted angiogram with catheterization of the left L3 segmental artery. The coil was placed and detached. (b) Anteroposterior X-ray obtained while the left L3 segmental artery was still catheterized demonstrates the final coil position in reference to the bony anatomy.

day 1 , a computed tomography $(\mathrm{CT})$ angiography of the abdomen and pelvis showed postoperative changes and a right psoas collection of air and fluid. Also, on postoperative day 1 , the patient received a lumbosacral orthosis and had upright X-rays and standing scoliosis films which were satisfactory. On postoperative day 3 , the patient's hemoglobin reached its trough, $8.6 \mathrm{~g} / \mathrm{dl}$, after which it started to improve. The patient did not require transfusion. On postoperative day 4 , a repeat CT angiography of the abdomen and pelvis showed a persistent 
fluid collection in the right psoas major believed to be a hematoma or seroma. We discharged the patient without incident on postoperative day 10.

\section{Ethical Approval and Informed Consent}

Ethical approval was not required. Informed consent was obtained from the patient in this study, including consent for publication of the figures.

\section{DISCUSSION}

In this case, we have described a patient who suffered a left L3 segmental artery injury during ALL release as part of an ACR and his clinical course. Although in terms of vascular injury much of the focus is on injury to one of the great vessels, segmental artery injury is also a possible complication associated with this procedure. Overall, the literature discussing segmental artery injury in ACR surgery is sparse. In a survey on 13,004 patients, Uribe and Deukmedjian found only three reports of a segmental artery injury, indicating a very low incidence [8]. To our knowledge, none of these injuries has been described in the literature in any detail; thus, we sought to describe such an injury, its resolution, and the effects on the patient.

Although this complication is not common, we hypothesize some reasons why it occurred in this case and some factors to consider pre- and intraoperatively to reduce its prevalence even more. First, the patient was in his 60s and regularly smoked three packs of cigarettes per day. Increased age is a major risk factor for increased arterial tortuosity and also iatrogenic arterial injury [13-15]. Because of this increased tortuosity, the patient's arteries may be slightly distorted in anatomical location. For example, his segmental artery's branches can be seen at the same level as the disk space (Figure 2) and closer in laterality to the disk space than one might typically expect, increasing the potential for injury. In addition, in a paper analyzing anterior approach lumbar spine surgeries, Fantini et al. found that anterior osteophytes increased the risk of vascular injury, likely because the increased inflammation results in the blood vessels being more fixed and resistant to movement [16]. While our patient had some anterior osteophytes (see Figure 1), he also had some significant lateral osteophytes. Thus, it is possible that the artery was at increased risk for shear injury given its resistance to outside motion.

Iatrogenic arterial injuries are an increasingly recognized cause of arterial injuries even at major trauma centers, although neurological surgery is not a common culprit $[15,17]$. Fortunately, our patient had no associated morbidity. However, his hemoglobin level did drop by about five points after the procedure and associated arterial injury-although he was never symptomatic from his anemia, nor did he need blood transfusions. Additionally, by good luck, our vascular colleagues were available for intraoperative consultation so we could address the injury immediately and, as it happened, endovascularly. Nevertheless, this complication is an important one to be aware of during ALL release.

\section{CONCLUSIONS}

Segmental artery injury during ACR is a very rare, but possible, complication. This injury can be treated concurrently with endovascular embolization if equipment and personnel are readily available. Increased arterial tortuosity and significant osteophytes may increase the risk of arterial injury. However, segmental artery injury does not appear to be as morbid as great vessel injury.

\section{Ethics Statement}

(1) All the authors mentioned in the manuscript have agreed to authorship, read and approved the manuscript, and given consent for submission and subsequent publication of the manuscript.

(2) The authors declare that they have read and abided by the JEVTM statement of ethical standards including rules of informed consent and ethical committee approval as stated in the article.

\section{Conflicts of Interest}

The authors declare that they have no conflicts of interest.

\section{Funding}

The authors received no financial support for the research, authorship, and/or publication of this article.

\section{REFERENCES}

[1] Glassman SD, Berven S, Bridwell K, Horton W, Dimar JR. Correlation of radiographic parameters and clinical symptoms in adult scoliosis. Spine. 2005;30:682-8. doi:10.1097/01.brs.0000155425.04536.f7.

[2] Mac-Thiong JM, Transfeldt EE, Mehbod AA, et al. Can c7 plumbline and gravity line predict health related quality of life in adult scoliosis? Spine. 2009;34:E51927. doi:10.1097/BRS.0b013e3181a9c7ad.

[3] Glassman SD, Bridwell K, Dimar JR, Horton W, Berven S, Schwab F. The impact of positive sagittal balance in adult spinal deformity. Spine. 2005;30:2024-9. doi:10.1097/01.brs.0000179086.30449.96.

[4] Godzik J, Pereira BA, Hemphill C, Walker CT, Wewel JT, Turner JD, Uribe JS. Minimally invasive anterior longitudinal ligament release for anterior column realignment. Global Spine J. 2020;10:101s-10s. doi:10. 1177/2192568219880178.

[5] Saigal R, Mundis GM Jr, Eastlack R, Uribe JS, Phillips FM, Akbarnia BA. Anterior column realignment (ACR) in adult sagittal deformity correction: technique and 
review of the literature. Spine. 2016;41(Suppl 8):S6673. doi:10.1097/brs.0000000000001483.

[6] Akbarnia BA, Mundis GM Jr, Moazzaz P, et al. Anterior column realignment (ACR) for focal kyphotic spinal deformity using a lateral transpsoas approach and ALL release. J Spinal Disord Tech. 2014;27:29-39. doi: 10.1097/BSD.0b013e318287bdc1.

[7] Murray G, Beckman J, Bach K, Smith DA, Dakwar E, Uribe JS. Complications and neurological deficits following minimally invasive anterior column release for adult spinal deformity: a retrospective study. Eur Spine J. 2015; 24(Suppl 3):397-404. doi:10.1007/s00586-015-3894-1.

[8] Uribe JS, Deukmedjian AR. Visceral, vascular, and wound complications following over 13,000 lateral interbody fusions: a survey study and literature review. Eur Spine J. 2015;24(Suppl 3):386-96. doi:10.1007/ s00586-015-3806-4.

[9] Balsano M, Carlucci S, Ose M, Boriani L. A case report of a rare complication of bowel perforation in extreme lateral interbody fusion. Eur Spine J. 2015;24(Suppl 3): 405-8. doi:10.1007/s00586-015-3881-6.

[10] Tormenti MJ, Maserati MB, Bonfield CM, Okonkwo DO, Kanter AS. Complications and radiographic correction in adult scoliosis following combined transpsoas extreme lateral interbody fusion and posterior pedicle screw instrumentation. Neurosurg Focus. 2010;28:E7. doi:10.3171/2010.1.Focus09263.

[11] Assina R, Majmundar NJ, Herschman Y, Heary RF. First report of major vascular injury due to lateral transpsoas approach leading to fatality. J Neurosurg Spine. 2014;21:794-8. doi:10.3171/2014.7. Spine131146.

[12] Aichmair A, Fantini GA, Garvin S, Beckman J, Girardi FP. Aortic perforation during lateral lumbar interbody fusion. J Spinal Disord Tech. 2015;28:71-5. doi:10.1097/ bsd.0000000000000067.

[13] Cha KS, Kim MH, Kim HJ. Prevalence and clinical predictors of severe tortuosity of right subclavian artery in patients undergoing transradial coronary angiography. Am J Cardiol. 2003;92:1220-2. doi:10.1016/j.amjcard. 2003.07.038.

[14] Del Corso L, Moruzzo D, Conte B, et al. Tortuosity, kinking, and coiling of the carotid artery: expression of atherosclerosis or aging? Angiology. 1998;49:361-71. doi:10.1177/000331979804900505.

[15] Rudström H, Bergqvist D, Ogren M, Björck M. Iatrogenic vascular injuries in Sweden. A nationwide study 1987-2005. Eur J Vasc Endovasc Surg. 2008;35:131138. doi:10.1016/j.ejvs.2007.09.010.

[16] Fantini GA, Pappou IP, Girardi FP, Sandhu HS, Cammisa FP Jr. Major vascular injury during anterior lumbar spinal surgery: incidence, risk factors, and management. Spine. 2007;32:2751-8. doi:10.1097/BRS. 0b013e31815a996e.

[17] Giswold ME, Landry GJ, Taylor LM, Moneta GL. Iatrogenic arterial injury is an increasingly important cause of arterial trauma. Am J Surg. 2004;187:590-3. doi: 10.1016/j.amjsurg.2004.01.013. 